\title{
MENINGKATKAN HASIL BELAJAR MATEMATIKA MATERI BANGUN RUANG MENGGUNAKAN MODEL PEMBELAJARAN KOOPERATIF TIPE STAD SISWA KELAS VI SDS 2 KRISTEN \\ Improving Mathematics Learning Outcomes For Building Space Materials Using Cooperative Learning Model Type Stad Students Of Class Vi Sds 2 Christian
}

\author{
Oleh: Esni \\ e-mail: esnis.pd1972@gmail.com
}

\begin{abstract}
ABSTRAK
Penelitian ini dilaksanakan untuk mengetahui pembelajaran matematika melalui model pembelajaran kooperatif tipe STAD dapat meningkatkan hasil belajar siswa dalam menyelesaikan soal-soal pada materi bangun ruang.

Subjek Penelitian Tindakan Kelas ini adalah siswa Kelas VI SDS 2 Kristen ,dengan jumlah siswa 11 orang, terdiri dari 8 siswa putra dan 3 siswa putri. Secara geografis memang letak SDS 2 Kristen terletak di kelurahan. Dengan latar belakang pendidikan orang tua $\pm 48 \%$ $\mathrm{SD}, \pm 24 \%$ SMP dan $\pm 28 \%$ SMA. Sedangkan latar belakang ekonomi orang tua $\pm 45 \%$ buruh tani, $\pm 50 \%$ petani dan sisanya pedagang. Kondisi semacam ini menyebabkan motivasi belajar siswa Kelas VI SDS 2 Kristen sedikit rendah. Hasil pengamatan sementara hanya 47\% siswa yang bisa menyelesaikan pekerjaan materi Bangun Ruang dengan baik melalui penggunaan pembelajaran model STAD (Student Team Achievement Division). Peneliti adalah guru di SDS 2 Kristen berkolaborasi dengan guru kelas yang lain di SDS 2 Kristen.

Berdasarkan hasil penelitian bahwa model pembelajaran kooperatif tipe STAD mata pembelajaran matematika pada materi Bangun Ruang dapat meningkatkan hasil belajar siswa. Siklus I setelah dilakukan pembelajaran matematika dengan model kooperatif tipe STAD. Skor rata-rata hasil belajar siswa adalah 64,00. Siklus II skor rata-rata hasil belajar siswa pada pokok bahasan Bangun Ruang adalah 79,20.
\end{abstract}

Kata Kunci : Kemampuan Belajar Matematika, Bangun Ruang, Kooperatif Tipe Stad.

\section{ABSTRACT}

This research was conducted to determine the learning of mathematics through cooperative learning model type STAD can improve student learning outcomes in solving problems on the material wake up space.

The subjects of this Classroom Action Research were students of Class VI SDS 2 Kristen, with a total of 11 students, consisting of 8 male students and 3 female students. Geographically, SDS 2 Kristen is located in an urban village. With parental educational background $\pm 48 \%$ elementary school, $\pm 24 \%$ junior high school and $\pm 28 \%$ high school. While the economic background of parents is $\pm 45 \%$ farm laborers, $\pm 50 \%$ farmers and the rest are traders. This condition causes the learning motivation of the sixth grade Christian SDS 2 students to be a little low. The results of temporary observations are only 47\% of students who can complete the work of building space well through the use of the STAD (Student Team Achievement Division) learning model. The researcher is a teacher at SDS 2 Kristen collaborating with other classroom teachers at SDS 2 Kristen.

Based on the results of the study that the STAD type cooperative learning model in mathematics learning in the Building Space material can improve student learning outcomes.

Cycle I after learning mathematics with the STAD type cooperative model. The average score of student learning outcomes is 64.00. Cycle II the average score of student learning outcomes on the subject of Building Space is 79.20.

Keywords : Ability to Learn Mathematics, Build Space, Cooperative Type Stad. 


\section{PENDAHULUAN}

Saat ini, ilmu pengetahuan dan teknologi berkembang sangat pesat. Orang dengan segala masalah dan aktivitasnya perlu aktif agar dapat memantau situasi dan menyelesaikan setiap masalah yang dihadapinya saat ini. Tentunya dalam menyelesaikan semua masalah, kita menginginkan kecerdasan, kreativitas, dan intuisi agar pemecahan masalah tidak menimbulkan masalah yang lebih sulit. Untuk melatih manusia yang berkualitas, tentunya pendidikan global tidak dapat dipisahkan. karena pendidikan merupakan tempat lahirnya generasi yang berkualitas dan mandiri. Oleh karena itu, pendidikan harus berkualitas baik.

Peningkatan mutu pendidikan dan pengajaran harus selalu diupayakan dan dilaksanakan dengan meningkatkan mutu pembelajaran. Dengan meningkatkan kualitas pembelajaran, siswa akan memiliki motivasi belajar yang lebih, kreativitas yang lebih, sikap belajar yang lebih aktif, jenis pengetahuan dan penguasaan keterampilan yang lebih besar, pemahaman yang lebih kokoh terhadap materi yang dipelajari.

Dalam upaya meningkatkan mutu pendidikan di tingkat nasional, dilakukan kajian terhadap kurikulum. sehingga perbaikan kurikulum terjadi dari waktu ke waktu. Kesalahan lainnya adalah penggunaan KTSP (Kurikulum Tingkat Satuan Pendidikan), suatu proses pembelajaran yang menekankan pada pemberian pengalaman langsung untuk mengembangkan kemampuan menggali dan memahami sedikit banyak sifat seorang ilmuwan. Menurut hukum n. 20 Tahun 2003 tentang sistem pendidikan nasional, pendidikan nasional bertujuan untuk berkembangnya potensi peserta didik agar menjadi manusia yang beriman dan bertakwa kepada Tuhan Yang Esni
Maha Esa, berakhlak mulia dan menikmati kesehatan yang baik, cakap, cakap, kreatif. , kemerdekaan dan kewarganegaraan negara, demokrasi dan tanggung jawab (Anwar Arifin: 2003). Salah satu tujuan di atas dapat dicapai melalui proses pembelajaran matematika.

Tujuan pembelajaran matematika pada Program Studi 2006 (KTSP) adalah agar siswa memiliki keterampilan sebagai berikut (Depdiknas, 2006: 135)

Memahami konsep matematika, menjelaskan keterkaitan antar konsep, dan menerapkan konsep Algoritma, secara fleksibel, akurat, efisien dan cara praktis, memecahkan masalah. Ini menggunakan penalaran pola dan karakterisasi, melakukan operasi matematika dengan membuat generalisasi, membangun bukti, atau menjelaskan ide dan pernyataan matematika. Pemecahan masalah meliputi kemampuan memahami masalah, merancang model matematika, melengkapi model, dan menginterpretasikan solusi yang diperoleh.

Mengkomunikasikan ide menggunakan simbol, bagan, diagram, atau cara lain untuk menggambarkan situasi atau masalah. memiliki sikap menghargai kegunaan matematika dalam kehidupan, rasa ingin tahu, perhatian, suka belajar matematika, memiliki sikap ulet dan percaya diri saat memecahkan dilema. Oleh karena itu, kegiatan matematika yang dilakukan harus selalu mengarah pada tujuan di atas, dengan memperhatikan karakteristik siswa yang menjadi pembelajar. Agar proses pembelajaran berlangsung efektif, guru perlu memperhatikan faktor-faktor berikut (Mohamad Matahari, 2006): 1). pembagian tujuan yang terstruktur; Milik mereka). Memotivasi siswa; 3). Contoh penggunaan; 4). pesanan pasokan; 5). hadiah dalam perang 
pertama; 6). Kerangka kerja pelatihan yang efektif; 7). masalah kesenjangan individu; 8). penilaian dan bimbingan; 9). upaya untuk menghafal; 10). Donasikan perangkat lunak karena pembelajaran. Masih banyak siswa di SD (Sekolah Dasar) khususnya kelas VI yang mengalami kesulitan dalam mempelajari perkalian dan pembagian. Hal ini bertentangan dengan tujuan matematika dasar, yaitu mengutamakan siswa yang mampu memahami, mengenal, dan menguasai sapta daripada penggunaannya dalam kehidupan sehari-hari (Ruseffendi, 1988).

Sesuai yang akan terjadi analisis terhadap nilai ulangan harian mata pelajaran matematika terutama dalam standar kompetensi Geometri dan Pengukuran yaitu memahami sifat bangun ruang sederhana seta menghitung volume bangun ruang tersebut pada peserta didik Kelas VI didapat bahwa prestasi belajar matematika peserta didik masih rendah.liputan di atas membagikan bahwa sebagian akbar siswa masih mengalami kesulitan pada memahami mata pelajaran matematika. Hal ini mungkin disebabkan sang pendekatan, seni manajemen, model, atau metode yang diterapkan oleh guru kurang sinkron, pula kemampuan pengajar serta sarana pembelajaran yang mencakup media, indera peraga, dan buku pegangan peserta didik yang terbatas, atau sebab lain yang tidak diketahui.

Oleh sebab itu penggunaan metode pembelajaran dirasa sangat penting buat membantu peserta didik dalam tahu konsepkonsep matematika.Metode pembelajaran jenisnya beragam yang masing-masing mempunyai kelebihan dan kelemahan, maka pemilihan metode yang sesuai menggunakan topik atau utama bahasan yang akan diajarkan harus betul-betul dipikirkan oleh Esni

guru yang akan menyampaikan materi pelajaran. Sedangkan penggunaan metode STAD diperlukan dapat menaikkan aktivitas peserta didik pada proses belajar mengajar sehingga pada proses belajar mengajar itu aktivitasnya tidak hanya didominasi sang guru, dengan demikian siswa akan terlibat secara fisik, emosional serta intelektual yang di gilirannya dibutuhkan konsep perubahan benda yang diajarkan oleh pengajar dapat dipahami oleh siswa.

Matematika sekolah itu bagian asal matematika yang dipilih antara lain menggunakan berorientasi pada kependidikan. dengan demikian dalam pembelajaran matematika perlu diusahakan sesuai menggunakan kemampuan kognitif siswa, mengkonkritkan objek matematika yang tak berbentuk sebagai mudah dipahami peserta didik. Hal ini ditimbulkan anak seusia SD masih pada pola berpikir kongkrit, yaitu berpikir yang didasari sang manipulasi fisik asal objek-objek atau benda-benda konkrit (Piaget dalam surya, 2007:1.36). Setiap konsep matematika bisa dipahami dengan simpel apabila hambatan primer yang menyebabkan anak sulit tahu dapat dikurangi. Anak pada umumnya melakukan abstraksi sesuai pengalaman konkrit, sebagai akibatnya mengajarkan matematika bisa dilakukan memakai objek-objek konkrit serta permainan-permainan matematika (Diemas pada Ruseffendi,1988:11).

Model pembelajaran kooperatif banyak mengilhami lahirnya contoh-model pembelajaran mutakhir yang berpusat di peserta didik. Pembelajaran kooperatif asal dari kata "kooperatif" yang merupakan mengerjakan sesuatu secara beserta-sama menggunakan saling membantu satu sama lainnya menjadi satu grup atau satu tim. Slavin mengemukakan bahwa pembelajaran kooperatif artinya suatu model pembelajaran kooperatif artinya suatu model pembelajaran 
dimana sistem belajar serta bekerja dalam grup-gerombolan kecil yang berjumlah 4-6 orang secara kolaboratif sehingga bisa merangsang siswa lebih bergairah pada belajar.(Isjoni, 2009:22). dalam penelitian ini, peneliti memakai pembelajaran kooperatif dengan contoh Student Team Achievement Division (STAD). contoh ini dikembangkan Slavin, serta ialah salah satu contoh kooperatif yang menekankan di adanya aktifitas serta saling membantu dalam menguasai pelajaran guna mencapai prestasi yang aporisma.

Pada mengajarkan matematika perlu adanya media pembelajaran yang dapat membantu peserta didik buat lebih praktis memahami suatu konsep. Bila memakai media pembelajaran, supaya diperhatikan supaya alat peraga itu, antara lain (Ruseffendi, 1988:3): 1). Tahan usang, dua). Bentuk dan warnanya menarik, 3). Sederhana serta praktis diolah (tak rumit), 4). Ukurannya sinkron (seimbang) dengan ukuran fisik anak, 5). disajikan dalam bentuk real (konkret), gambar atau diagram konsep IPS, 6). sesuai dengan konsep, 7). dapat memberikan konsep IPS dengan jelas, 8). Peragaan itu agar adalah dasar bagi tumbuhnya konsep abstrak, 9). bisa dimanipulasi yaitu bisa diraba, dipegang, dipindah, dan diutak-atik, atau dipasang serta dilepas sehingga siswa dapat belajar kreatif baik sendiri juga berkelompok.

Media pembelajaran berfungsi buat menurunkan keabstrakan konsep supaya siswa bisa menangkap konsep tersebut. dengan menggunakan media pembelajaran dalam pembelajaran matematika dimaksudkan supaya siswa bisa mengoptimalkan panca alat dalam proses pembelajaran, sebab siswa dapat melihat, meraba, mencicipi serta mampu menggunakan objek yang dipelajari. 
6) Perencanaan lembar observasi kegiatan guru Siklus I

7) Perencanaan lembar angket tanggapan siswa Siklus

Sebelum melaksanakan pembelajaran pada siklus I, guru menyampaikan tes awal siklus serta diberikan di hari sebelumnya di luar pembelajaran. lalu tes refleksi awal dikumpulkan dan dianalisis buat dijadikan acuan dalam pembuatan daftar grup di masing-masing daur secara heterogen berdasarkan taraf kemampuan akademik. asal yang akan terjadi tes refleksi awal pula dikumpulkan menjadi asal data serta pengolahan data pada akhir penelitian. pada tahap acting/tindakan ini dilakukan sekaligus dengan observasi terhadap proses pembelajaran melalui penggunaan model STAD (Student Team Achievement Division) secara terang menjadi berikut :

Guru melakukan apersepsi, guru mengulang kembali materi bangun datar dan bangun ruang yang diajarkan di kelas VI.

a. Coba sebutkan nama-nama bangun datar yang kalian ketahui!

b. Kalian tahu apa rumus untuk mencari luas persegi dan persegi panjang?

c. Coba sebutkan nama-nama bangun ruang yang kalian ketahui!

1. Pengajar motivasi buat mengarahkan siswa memasuki materi bangun ruang yang akan dibahas.

2. Guru mengungkapkan tujuan pembelajaran yang akan dicapai.

3. Guru menjelaskan langkah kerja model pembelajaran kooperatif menggunakan tipe STAD.

4. Guru membimbing peserta didik buat berkelompok menggunakan lima siswa setiap kelompok duduk berhadapan. gerombolan didasarkan di pengetahuan siswa tentang matematika khususnya materi bangun datar dan bangun ruang yang telah diajarkan di kelas VI.

5. Dengan memakai Media Pembelajaran berupa aneka bentuk bangun ruang, guru mempresentasikan pengetahuan deklaratif perihal sifat-sifat serta jaringjaring bangun ruang, dan memotivasi siswa supaya menjadi pendengar yang baik.

6. Pengajar membagi lembar kerja LKS di semua gerombolan buat diselesaikan. Selanjutnya, berkeliling ke setiap gerombolan . Pengajar bersama kolabolator mengamati kerja setiap grup dan memberikan pengarahan pada grup yang memerlukan serta mencatat kejadian atau hal-hal krusial pada lembar catatan lapangan.

7. Guru beserta siswa dengan tanya jawab membahas pemasalahan pada setiap grup.

8. Pengajar memberikan tes akhir daur I buat dikerjakan secara individu.

9. Secara klasikal guru menekankan materi krusial yang harus dipelajari peserta didik serta merangkum materi.

10. Pengajar membimbing siswa buat mengisi lbr angket yang sebelumnya telah dibagikan.

11. Guru memberi istilah-kata kebanggaan pada peserta didik atas keaktifan dankesungguhannya pada mengikuti proses pembelajaran.

Pada tahap ini, peneliti dengan bimbingan kolabolator melakukan refleksi terhadap pembelajaran pada Siklus I untuk kemudian dijadikan acuan perbaikan planning pada pertemuan berikutnya. Hal yang akan dilakukan oleh peneliti adalah sebagai berikut: Peneliti akan melakukan analisis dan perbandingan nilai hasil tes akhir siklus I dengan nilai tes refleksi awal. Dengan demikian, dapat diketahui peningkatan hasil belajar yang telah dicapai. 
Berdasarkan hasil tes akhir Siklus I, maka akan dilakukan revisi planning pada proses Siklus II.

Hasil observasi aktivitas siswa selama proses pembelajaran berlangsung akan dijadikan acuan untuk mengubah komposisi kelompok. Pada Siklus I, siswa dikelompokkan berdasarkan nilai hasil refleksi awal. Jika komposisi kelompok tersebut belum menunjukkan hasil maksimal dalam artian prosentase siswa yang pasif masih besar, maka pada siklus berikutnya dalam setiap kelompok, diusahakan terdiri dari siswa yang berkemampuan tinggi, sedang dan rendah. Dengan demikian, dalam menyelesaikan tugas kelompok, siswa yang berkemampuan lebih tinggi dapat membantu siswa yang berkemampuan dibawahnya.

\section{Siklus II}

Berdasarkan hasil refleksi pada siklus I, pada tahap ini dilakukan perencanaan sebagai berikut :

1) Perencanaan Daftar Kelompok Siklus II

2) Perencanaan Rencana Pelaksanaan Pembelajaran (RPP) Siklus II

3) Perencanaan Lembar kerja LKS siklus II

4) Perencanaan lembar pengamatan aktivitas siswa

5) Perencanaan lembar pengamatan kegiatan guru

6) Perencanaan lembar angket tanggapan siswa Siklus II

7) Perencanaan evaluasi akhir siklus, yaitu Soal tes dan Kunci soal tes akhir siklus II.

\section{Pelaksanaan Rencana\& Observasi}

1) Guru melakukan apersepsi, guru mengulang kembali materi bangun ruang pada pertemuan sebelumnya.

a. Coba sebutkan bangun ruang yang kalian tahu!

b. Berapa jumlah sisi dari bangun ruang kerucut?

c. Berapa jumlah rusuk dari bangun ruang balok?

2) Guru motivasi untuk mengarahkan siswa memasuki materi menghitung volume kubus dan balok yang akan dibahas.

3) Guru menjelaskan tujuan pembelajaran yang akan dicapai.

4) Guru meminta siswa untuk duduk sesuai kelompok baru yang telah ditentukan.

5) Dengan memegang Media Pembelajaran, guru menjelaskan tentang cara menghitung volume kubus dan balok, sedangkan kolabolator mengamati.

6) Guru membagi lembar kerja LKS pada semua kelompok untuk diselesaikan. Selanjutnya, berkeliling ke setiap kelompok. Guru bersama kolabolator mengamati kerja setiap kelompok dan memberikan pengarahan pada kelompok yang memerlukan serta mencatat kejadian atau hal-hal penting pada lembar catatan lapangan.

7) Guru bersama siswa dengan tanya jawab membahas pemasalahan pada setiap kelompok.

8) Guru memberikan tes tertulis untuk dikerjakan secara individu.

9) Secara klasikal guru menekankan materi penting yang harus dipelajari siswa dan merangkum materi.

10) Guru membimbing siswa untuk mengisi lembar angket yang sebelumnya telah dibagikan.

11) Guru memberi kata-kata pujian kepada siswa atas keaktifan dan kesungguhannya dalam mengikuti proses pembelajaran.

\section{KESIMPULAN}

Berdasarkan hasil penelitian ialah bahwa Pada siklus I atau setelah dilakukan 
pembelajaran matematika dengan model pembelajaran kooperatif tipe STAD, skor rata-rata hasil belajar siswa pada pokok bahasan Bangun Ruang adalah 68,00 dari skor ideal yang mungkin dicapai 100,00. Pada siklus II atau setelah dilakukan pembelajaran matematika dengan model pembelajaran kooperatif tipe STAD, skor rata-rata hasil belajar siswa pada pokok bahasan Bangun Ruang adalah 79,20 dari skor ideal yang mungkin dicapai 100,00.

\section{DAFTAR PUSTAKA}

Arifin, Anwar ,.2003 .Memahami Paradigma Baru Pendidikan Nasional dalam UU Sisdiknas .Jakarta : Depag

Basrowi, Suwandi. 2008 . Prosedur Penelitian Tindakan Kelas . Bogor : Ghalia Indonesia.

Depdiknas. 2008 . Kurikulum Kelas VI SD . Jakarta : Depdiknas.

Depdiknas. 2008 . Peraturan Menteri Pendidikan Nasional. Jakarta : Depdiknas

Gatot Muhsetyo. 2009 . Pembelajaran Matematika SD . Jakarta : Universitas Terbuka.

Isjoni. 2009 . Pembelajaran Kooperatif . Yogyakarta :Penerbit Pustaka Pelajar

Iskandar . 2009 . Penelitian Tindakan Kelas . Ciputat : Gaung Persada

Karso. 2007 . Pendidikan Matematika I . Jakarta : Universitas Terbuka.

Khafid,M, Suyati . 2002 . Pelajaran Matematika Penekanan pada Berhitung 5. Yogyakarta : Penerbit Erlangga.

Riadin Agung dan Uswatun Nisa. 2017. Upaya Meningkatkan Hasil Belajar Matematika Dengan Menerapkan Model Pembelalajaran Langsung Menggunakan Media Mobil Garis Bilangan Tahun Pelajaran 2016/2017. Pedagogik: Jurnal Pendidikan. 12:2(28-33).
Ruseffendi, E.T. 1988 . Pengajaran Matematika Modern dan Masa Kini Seri Pertama . Bandung : Tarsito.

Ruseffendi, E.T. 1988 . Pengajaran Matematika Modern dan Masa Kini Seri Ke Lima . Bandung : Tarsito.

Setiawan Muhammad Andi dan Izha Suci Maghfirah. 2021. Efektivitas Aplikasi Zoom Dalam Proses Pembelajaran Matematika. Bitnet: Jurnal Pendidikan Teknologi Informasi, 6:1(33-37).

Soenarjo. 2008 . Matematika IV . Jakarta : Pusat Pembukuan, Depdiknas.

Surya, Mohamad . 2005 . Psikologi Pembelajaran dan Pengajaran . Jakarta : Pustaka Bani Quraisy

Surya, Muhammad. 2007 . Dasar - Dasar Kependidikan di SD. Jakarta : Universitas Terbuka. 